\title{
Pneumocystis carinii pneumonia
}

\author{
Robert F Miller, David M Mitchell
}

During the first 10 years of the AIDS pandemic the clinical features of the syndrome have been extensively reported. By January 1992 there had been 5451 cases of AIDS in the United Kingdom, 3391 patients having died, and 16828 people were known to have antibodies to the human immunodeficiency virus (HIV), with the potential to progress to AIDS. Pneumocystis carinii pneumonia, despite widespread use of effective prophylaxis, remains the most common opportunist infection in patients with AIDS.

In the two years since the articles in the series AIDS and the lung appeared in Thorax there have been important developments in the clinical management of respiratory complications of $\mathrm{HIV}$ infection, and there is also a clearer understanding of the molecular biology of the infectious complications. In this article, the first of two updates, we review recent advances in the molecular biology and clinical management of patients with Pneumocystis carinii infection.

\section{Molecular biology of Pneumocystis carinii pneumonia}

Two morphological forms of $P$ carinii are seen in infected lungs: thin walled, irregularly shaped, single nucleảted trophozoites (2$5 \mu \mathrm{m})$, which adhere firmly to the external surface of type 1 pneumocytes, and thick walled cysts $(7-6 \mu \mathrm{m})$ containing four to eight single nucleated sporozoites, which lie freely within the alveoli. Uncertainties surround the taxonomy of $P$ carinii. Its morphological features, including the irregular shaped trophozoites and the absence of motility organelles; the silver staining of the cyst walls; the chemotherapeutic response to antiprotozoal drugs, including pentamidine, though not to antifungal drugs such as amphotericin B; and the failure to culture the organisms in various media have led to the view that the organism is either a protozoon or a fungus.

Serological studies using indirect fluorescence, enzyme linked immunosorbent assays, and Western blotting (immunoblotting) have shown that healthy children and adults, as well as those with pneumocystis pneumonia, have a high frequency of serum antibodies to the organism. ${ }^{12}$ This has led to the suggestion that asymptomatic infection occurs in childhood. It has also been widely assumed that opportunist pneumocystis pneumonia in patients immunosuppressed by malignancy, chemotherapy, corticosteroids, or HIV results from reactivation from a focus of organisms in the lungs that may, by analogy with tuberculosis, be the residuum of asymptomatic, self healed childhood infection. This assumption has recently been challenged by the application of molecular biology to the study of $P$ carinii.

\section{Cloning of DNA from Pneumocystis carinii}

The unique properties of organisms are precisely expressed at a genetic level, being defined by the sequence of nucleic acid bases in their DNA (or RNA in certain viruses). Part of the gene coding for the large subunit of the mitochondrial ribosomal RNA from $P$ carinii has been cloned and sequenced. $P$ carinii pneumonia was induced in the rat and DNA was extracted and cloned from parasite enriched fractions from the lungs. ${ }^{3}$ Identification of recombinants of non-rat origin (that is from pneumocystis) was achieved by negative colony hybridisation and probing with genomic rat DNA. Recombinants of interest were tested in an in situ hybridisation assay with sequences obtained from human and rat lungs infected and not infected with $P$ carinii. ${ }^{3}$ Sequences specific for $P$ carinii were confirmed by their characteristic in situ hybridisation patterns, which were typical of the morphology and distribution of $P$ carinii infection in lung tissue. ${ }^{3}$ Recombinant plasmid PAZ102 was selected as a candidate mitochondrial sequence because of strong signals derived in hybridisation studies on infected lung samples. The plasmid PAZ102 (an insert of 570 base pairs) was sequenced and compared with several data bases. From sequence data on PAZ102 and comparative analysis of data bases the fragment was identified as a portion of the gene coding for the large subunit of mitochondrial ribosomal RNA of $P$ carinii.

Oligonucleotide primers used for the polymerase chain reaction were constructed from two sequences of moderate conservation that were specific to $P$ carinii-PAZ102-E: 5'-GATGGCTGTTCCAAGCCCA-3' and PAZ102-H: 5'-GTGTACGTTGCAAAGTACTC-3'. These oligonucleotides produced amplification of specific sequences from both rat and human bronchoalveolar lavage samples infected with $P$ carinii, but not from samples 


\begin{tabular}{l|l|l|l|l|l|l|l}
\cline { 2 - 3 } PAZ102-L1:5' & ATAAGGT & GAGG & AGTCGA & G & AG & $-3^{\prime}$ \\
PAZ102-L2:5' & ATAAGGT & AGAT & AGTCGA & A & AG & $-3^{\prime}$ \\
& & &
\end{tabular}

Comparative sequences of $P A Z$ 102-L1 rat specific oligonucleotide (top) and $P A Z 102-L 2$, which is human specific. The sequences of base pairs within the boxed areas are identical. Outside the boxes there are five base pair differences in the two oligonucleotides. infected with a range of other organisms, including Candida albicans, Mycobacterium tuberculosis, Cryptococcus neoformans, and Aspergillus nidulans.

An internal oligonucleotide, PAZ102-L1, derived from rat $P$ carinii produced strong hybridisation signals from Southern hybridisation with amplified products from infected rat lungs but only very weak signals with products from infected human lungs. ${ }^{4}$ Direct sequencing of the amplified products from both rat and human samples showed limited but consistent differences between the $P$ carinii DNA from these two hosts, ${ }^{5}$ which included five base changes in the sequence of the internal oligonucleotide PAZ102-L1 (figure). An oligonucleotide specific to the human derived organisms was constructed, PAZ102-L2. This showed strong hybridisation with the amplified product from human $P$ carinii but weak hybridisation with the rat $P$ carinii amplified product, ${ }^{4}$ indicating that natural infections in man and in the rat are due to different strains of $P$ carinil. A subsequen study has derived estimates of the sensitivity of DNA amplification methods by seeding homogenised human lung with $P$ carinii organisms derived from the immunosuppressed rat model. $A$ band of amplified DNA, made visible by ethidium bromide staining, was found to indicate the presence of 100 organisms or more. A band visible only with Southern hybridisation denoted smaller numbers of organisms, down to a lower limit of sensitivity of one or two organisms per sample. ${ }^{6}$

Is $\boldsymbol{P}$ carinii a reactivation or a reinfection? Studies using monoclonal antibody binding to screen postmortem lungs from immunocompetent and immunosuppressed patients who had died of causes other than pneumonia failed to detect $P$ carinii and challenged the theory of carriage of latent parasites in normal lungs. ${ }^{7}$ The theory was tested further by using DNA amplification with PAZ102-E and PAZ102-H and Southern hybridisation using PAZ102-L2 to search for $P$ carinii in postmortem lung samples from 15 nonimmunosuppressed individuals, who had died from various causes; none had primary lung disease. ${ }^{8}$ No $P$ carinii specific DNA amplification product was detected either by ethidium bromide staining or by Southern hybridisation in any of the specimens. ${ }^{8}$

Both silver staining and DNA amplificationoligoblotting were used to detect $P$ carinii from bronchoalveolar lavage fluid in 47 patients; 37 were immunosuppressed by HIV or by treatment for lymphoma, leukaemia, or vasculitis and 10 were immunocompetent and under- going bronchoscopy for investigation of various respiratory diseases. Of 15 immunosuppressed patients who had diagnoses other than $P$ carinii pneumonia (diagnosed by conventional silver staining), including pulmonary Kaposi's sarcoma and mycobacterial or bacterial infection, none had $P$ carinii DNA. detected by amplification and ethidium staining and only three had low levels of $\mathrm{DNA}^{6}$ detected by oligoblotting. ${ }^{9}$ No $P$ carinii DNA was detected by either DNA-amplification or oligobletting in samples from the immunocompetent group. A further study of 51 episodes of acute respiratory illness in $47 \mathrm{HIV}$ positive patients undergoing bronchoalveolar lavage included 20 episodes of $P$ carinii pneumonia and 31 respiratory episodes with other diagnoses. Silver staining gave negative results in all 31 episodes with other diagnoses. Seven of these patients had low levels of $P$ carinii DNA, detected by oligoblotting alone, and one patient with Staphylococcus aureus pneumonia had high levels of $P$ carinii DNA detectable in lavage fluid by ethidium staining. This patient had a past history of $P$ carinii pneumonia and presented again 10 weeks later with a second episode of pneumocystis pneumonia. Thus in these studies only 10 of 46 immunosuppressed patients had weak DNA signals, implying low levels of $P$ carinit, and strong signals were seen almost exclusively in those with P carinil pneumonia.

The absence of detectable $P$ carinii in these four studies ${ }^{7-10}$ does not support the view that there is long term pulmonary carriage of the organism, allowing reactivation during immunosuppression. Unless there is some other site for dormant organisms (and no data support such a hypothesis), reinfection would seem a more likely cause for pneumocystis pneumonia. Reports of case clusters of $P$ carinii pneumonia Juggest thra horizontal transmission may be important. " These data are important for epidemiological studies and emphasise the possibility of an environmental source of infection.

\section{Is Pneumocystis carinii a fungus or a protozoon?}

Two studies have suggested a degree of homology between fungi and $P$ carinii. These were based on analysis of $16 S$ and $5 S$ ribosomal RNA sequences. ${ }^{1314}$ Chance similarities may be observed, however, and misleading conclusions are likely if only one DNA sequence is studied. More recently a large (6.8 kilobase) fragment of $P$ carinii mitochondrial DNA, which contains seven continuous gene sequences coding for six proteins (parts of apocytochrome $b$ and NADH dehydrogenase subunit $I$ and all of subunits 2, 3, and 6 and cytochrome oxidase subunit 11) and a ribosomal RNA gene (the small subunit of ribosomal RNA) have been cloned and sequenced. ${ }^{15}$ Similarities between derived amino acid sequences for these six proteins and for sequences from three fungi (Neurospora crassa, Aspergillus nidulans, and Leishmania tarentolae) showed that $P$ carinii had the same 
degree of homology with the fungi as they did with each other. An average of $60 \%$ similarity to the fungi was seen, the closest being to Neurospora crassa. Protozoa were seen as a distinct and disparate group, showing only $20 \%$ similarity. ${ }^{5}$ This study indicates unequivocally that $P$ carinii has a greater degree of homology with fungi than with protozoa. These studies are rete planning strategies for culture of the organism in vitro and to devetoping drugs. In view of these close homologies with fungi it is interesting and perhaps paradoxical that antifungal drugs are ineffective.

\section{Investigation of Pneumocystis carinii pneumonia}

Empirical treatment for pneumocystis pneumonia in patients with typical symptoms, chest radiographic abnormalities, and hypoxaemia $^{16}$ may no longer be justifiable as pneumocystis pneumonia becomes less common in relation to bacterial infections and malignancy (including Kaposi's sarcoma) and as prior prophylaxis may modify its presentation. Diagnosis of pneumocystis pneumonia currently relies on identification of $P$ carinii in respiratory tract samples, either bronchoalveolar lavage fluid or induced sputum. We need a good screening test to identify HIV positive patients with respiratory symptoms who may have pneumocystis pneumonia before bronchoscopy is performed.

\section{TECHNETIUM-99M LABELLED}

DIETHYLENETRIAMENEPENTA-ACETIC ACID

Technetium-99m labelled diethylenetriamenepenta-acetic acid $\left({ }^{99 m}\right.$ Tc DTPA) scanning was compared with other non-invasive investigations including chest radiography, respiratory function tests (forced expiratory volume in one second, forced vital capacity, transfer factor, and carbon monoxide transfer coefficient) and arterial oxygen saturation at rest and during exercise in $13 \mathrm{HIV}$ positive patients with pneumocystis pumonia and 22 without (12 had bronchoscopy and 10-with bronchitis-did not; three had endobronchial Kaposi's sarcoma, six bacterial pneumonia, one tuberculosis, and three negative results in the investigations and self limiting episodes). ${ }^{99 \mathrm{~m}} \mathrm{Tc}$ DTPA aerosol was inhaled by patients sitting in front of a gamma camera for 45 minutes before bronchoscopy. ${ }^{17}$

There were no significant differences between the two groups in terms of lung function tests or arterial blood gas tensions at rest. Inhaled ${ }^{99 m}$ Tc DTPA had a faster median clearance half time in those with pneumocystis pneumonia (7.2 minutes) than in those without (22 minutes). The median arterial oxygen desaturation during exercise was $5 \%$ in those with pneumocystis pneumonia and $2 \%$ in those without. ${ }^{99 \mathrm{~m}} \mathrm{Tc}$ DTPA lung clearance was better than the other non-invasive tests in discriminating pneumocystis pneumonia from other pulmonary problems; and scanning for only seven minutes was just as specific and sensitive for the diagnosis of pneumocystis pneumonia as the longer time of $\mathbf{4 5}$ minutes.
${ }^{99 m}$ Tc DTPA was shown by this study to be a useful diagnostic test. If further studies in larger numbers of patients confirm that the scan time can be reduced to seven minutes, this technique could provide a rapid non-invasive screening test for pneumocystis pneumonia.

GALLIUM-67 SCANNING AND INDIUM-111 LABELLED HUMAN POLYCLONAL IMMUNOGLOBULIN SCANNING

Gallium-67 $\left({ }^{67} \mathrm{Ga}\right)$ scanning has been used in HIV positive patients with two distinct problems-firstly, in patients with dyspnoea or cough, or both, and normal chest radiographs in whom pneumocystis pneumonia is suspected and, secondly, in patients with abnormal chest radiographs known to have bronchopulmonary Kaposi's sarcoma in whom infection is suspected in addition. Gallium-67 is useful in this regard as it does net accumutate in Kaposi's sarcoma, but does accumulate in various infective and inflammatory conditions. ${ }^{119}$ The use of this imaging technique is limited, however, by the prolonged protocol of up to 72 hours.

Human polyclonal immunoglobulin labelled with indium-111 ( $\left.{ }^{111} \mathrm{In}\right)$ has been shown to localise sites of infection and inflammation. In rats immunosuppressed with steroid ${ }^{111}$ In labelled immunoglobulin was better than ${ }^{67} \mathrm{Ga}$ scanning for detecting pneumocystis pneumonia. ${ }^{111}$ In labelled immunoglobulin scans in rats with early pneumonia were abnormal whereas most gallium scans remained normal; rats with more advanced pneumonia showed a more intense diffuse intrapulmonary accumulation with ${ }^{111}$ In labelled immunoglobulin than with ${ }^{67} \mathrm{Ga}$. In rats with bacterial or fungal superinfection ${ }^{111}$ In labelled immunoglobulin scans showed patchy focal accumulation in addition to the diffuse accumulation whereas gallium scans showed no additional focal changes. ${ }^{20}$

${ }^{111}$ In labelled immunoglobulin scanning was used to investigate 13 HIV positive patients presenting with acute respiratory episodes. ${ }^{21}$ In three patients (two with pneumocystis pneumonia and one 'with Pseudomonas aeruginosa pneumonia) who had normal chest radiographs ${ }^{111}$ In labelled immunoglobulin scans showed diffuse intrapulmonary accumulation. Of eight patients with interstitial changes on the chest radiograph, ${ }^{111}$ In labelled immunoglobulin scans were negative in two with pulmonary Kaposi's sarcoma and showed diffuse intrapulmonary accumulation in six with pneumocystis pneumonia. Two further patients with pneumocystis infection (one had coinfection with Staphylococcus aureus), both with diffuse interstitial and alveolar radiographic abnormalities, had diffuse and focal intrapulmonary accumulation of ${ }^{111}$ In labelled immunoglobulin.

${ }^{111}$ In labelled immunoglobulin like ${ }^{67} \mathrm{Ga}$ scanning can distinguish between infection and Kaposi's sarcoma, but takes less time and gives a lower radiation dose to the patient.

SPUTUM INDUCTION

Sputum induction is a well established technique for diagnosing pneumocystis 
pneumonia $^{22}$ and other infections ${ }^{23}$ in HIV positive patients. The success rate varies considerably and not all centres have been able to establish the technique ${ }^{23}$ Steecss depends on several factors. Selection of patients is important; if only those with a high index of suspicion for pneumocystis pneumonia are studied then the yield is high. ${ }^{2}$ Patients need careful preparation and experienced têchnicians increase the success rate (so that samples representative of the lower respiratory tract are obtained). ${ }^{23}$

Adverse events have been reported. Arterial desaturation to $22 \%$ or less occurred and persisted for up to 20 minutes after the procedure in 11 of $20 \mathrm{HIV}$ positive patients with pneumocystis pneumonia and nine of 21 patients with other diagnoses. ${ }^{24}$ Neither the degree of chest radiographic abnormality, the alveolar-arterial oxygen gradient, nor baseline oxygen saturation identified patients who developed desaturation. ${ }^{24}$ Saturation fell to below $84 \%$ less than 10 minutes after the start of induction in two patients; the procedure was abandoned in these two and in two others, who developed nausea and retching. The fall in oxygen saturation was attributed to abnormalities of ventilation and perfusion ratios rather than to hypoventilation. The absence of desaturation seen in the control group suggested that desaturation occurs only in patients with abnormal lungs. The persistence of desaturation for up to 20 minutes after the procedure is important if other procedures, such as exercise testing, are to be carried out soon after sputuminduction.

TECHNIQUES TO INCREASE THE DIAGNOSTIC YIELD FOR PNEUMOCYSTIS CARINII FROM INDUCED SPUTUM AND BRONCHOALVEOLAR LAVAGE FLUID

Monoclonal antibodies

Several monoclonal antibodies specific for $P$ carinii are now available. Some recognise cysts (R13/3G4-6, 5E12) and others both cysts and trophozoites (2E3, 3FB, 2G2). Used in immunofluorescence tests, either singly or in cocktails, these antibodies have proved to be powerful diagnostic tools. $\mathrm{Ng}$ et al compared Grocott-Gomori, toluidine blue-O, Diff-Quick (a Giemsa like stain), and immunofluorescence tests on 182 specimens (128 of induced sputum and 56 of bronchoalveolar lavage fluid, one transbronchial biopsy specimen, and one open lung biopsy specimen). Use of indirect fluorescence antibodies (IFA) was better than all four conventional stains. $P$ carinii was detected by IFA in 17 cases where the four other stains gave a negative result. ${ }^{25}$

Several diagnostic kits incorporating different monoclonal antibodies are commercially available. Use of these kits increases the sensitivity and specificity of induced sputum or bronchoalveolar lavage fluid for diagnosis and reduces the time spent by staff scanning samples. Grocott staining may misidentify Histoplasma capsulatum or Cryptococcus neoformans as Pneumocystis carinii, whereas immunofluorescence tests substantially reduce this risk. ${ }^{26}$

\section{DNA amplification}

Bronchoalveolar lavage fluid Silver staining and DNA amplification were compared for the diagnosis of Pneumocystis carinii in 37 immunosuppressed patients (33 of whom were HIV positive) presenting with acute respiratory episodes. ${ }^{9}$ DNA amplification with ethidium bromide staining detected $P$ carinii DNA in all 16, were also silver stain positive. In six other patients, with negative silver stains, whose presentation and chest radiographs were typical of pneumocystis pneumonia DNA amplification gave a positive result in four; the other two patients were thought to have non-specific or lymphocytic pneumonitis.

Induced sputum DNA amplification and silver staining were used with bronchoalveolar lavage fluid and induced sputum for 51 epistes of respiratory illness in 47 HIV positive patients. ${ }^{10}$ Silver staining gave a positive result in $14(70 \%)$ bronchoalveolar lavage specimens and only seven (35\%) induced sputum samples, whereas DNA amplification with ethidium bromide staining was positive in 19 $(95 \%)$ lavage samples and $18(90 \%)$ induced sputum samples. Interestingly, DNA amplification gave a positive result for several indufed sputum samples that were judged "inadequate" as they contained only oral and pharyngeal debris that was silver stain negative. This raises the possibility that DNA amplification applied to saliva may provide a means of diagnosing $P$ carinii pneumonia.

\section{Treatment of Pneumocystis carinii pneumonia}

Intravenous high dose co-trimoxazole remains the "gold standard" treatment for pneumocystis pneumonia. Conventionally used doses of co-trimoxazole (sulphamethoxazole $100 \mathrm{mg}$ and trimethoprim $20 \mathrm{mg} / \mathrm{kg}$ a day) may be excessive. A study has shown that dose reduction to $75 \%$ of conventional doses, to maintain serum trimethoprim levels at $5-8 \mu \mathrm{g} / \mathrm{ml}$, was associated with a better toxicity profile but no reduction in efficacy. ${ }^{27}$ Recently oral treatment with co-trimoxazole, dapsone-trimethoprim, and the substituted naphthaquinolone BW566 have been shown to be effective in mild cases whereas routine use of high dose adjunctive glucocorticoids, in addition to parenteral antipneumocystis treatment, is now advocated for severe episodes.

The criteria used to stratify cases into mild, moderate, and severe Pneumocystis carinii pneumonia are shown in table 1 and appropriate treatment is shown in table 2 .

\section{THERAPY FOR PNEUMONIA OF MILD TO MODERATE SEVERITY}

\section{Dapsone-trimethoprim}

A double blind study of 60 patients with a first episode of pneumocystis pneumonia (mild to moderate) compared 21 days' oral treatment with trimethoprim-sulphamethoxazole (20/ $100 \mathrm{mg} / \mathrm{kg}$ a day) with trimethoprim-dapsone $(20 \mathrm{mg} / \mathrm{kg}$ a day and $100 \mathrm{mg}$ a day $){ }^{28}$

Oral treatment failed because of progressive 
Table 1 Grading of severity of Pneumocystis carinii pneumonia

\begin{tabular}{llll}
\hline & Mild & Moderate & Severe \\
\hline $\begin{array}{c}\text { Symptoms and } \\
\text { signs }\end{array}$ & $\begin{array}{c}\text { Increasing exertional } \\
\text { dyspnoea with or } \\
\text { without cough and } \\
\text { sweats }\end{array}$ & $\begin{array}{c}\text { Dyspnoea on minimal } \\
\text { exertion, occasional } \\
\text { dyspnoea at rest, } \\
\text { fever with or without } \\
\text { sweats }\end{array}$ & $\begin{array}{c}\text { Dyspnoea at rest, tachypnoea at rest, } \\
\text { persistent fever, cough }\end{array}$ \\
$\begin{array}{c}\text { Blood gas tensions } \\
\text { (room air) }\end{array}$ & $\begin{array}{c}\mathrm{PaO}_{2} \text { normal, } \mathrm{SaO}_{2} \\
\text { falling on exercise } \\
\begin{array}{c}\text { Chest radiograph } \\
\text { Normal or minor } \\
\text { perihilar shadowing }\end{array}\end{array}$ & $\begin{array}{c}\mathrm{PaO}_{2} 8 \cdot 1-11 \mathrm{kPa} \\
\text { Diffuse interstitial } \\
\text { shadowing }\end{array}$ & $\mathrm{PaO}_{2}<\mathbf{8 . 0 \mathrm { kPa }}$ \\
& & $\begin{array}{c}\text { Extensive interstitial shadowing } \\
\text { with or without diffuse alveolar } \\
\text { shadowing ("white out") sparing } \\
\text { costophrenic angles and apices }\end{array}$ \\
\hline
\end{tabular}

$\mathrm{PaO}_{2}$ - partial pressure of oxygen; $\mathrm{SaO}_{2}$-arterial oxygen saturation, measured with a transcutaneous oximeter.

Table 2 Treatment of Pneumocystis carinii pneumonia

\begin{tabular}{lll}
\hline & $\begin{array}{c}\text { Mild and } \\
\text { moderate }\end{array}$ & Severe \\
\hline Co-trimoxazole: & & \\
$\quad$ Intravenous & $\sqrt{ }$ & $\sqrt{ }$ \\
$\quad$ Oral & $\sqrt{ }$ & $\times$ \\
Dapsone-trimethoprim, oral & $\sqrt{ }$ & $\times$ \\
Pentamidine: & & \\
$\quad$ Intravenous & $\sqrt{ }$ & $\sqrt{ }$ \\
$\quad$ Nebulised & $\sqrt{ }$ & $\times$ \\
Clindamycin-primaquine & $\sqrt{ }$ & $\times$ \\
BW566 & $\sqrt{ }$ & $\times$ \\
Glucocorticoids & $\times$ & $\sqrt{ }$ \\
\hline
\end{tabular}

$\sqrt{ }$-Treatment feasible; $x$-treatment with this drug not shown to be effective, or data to support its use not available.

For definitions of mild, moderate, and severe see table 1 .

pneumonitis in only three of 30 patients given trimethoprim-sulphamethoxazole and in only two of 30 given trimethoprim-dapsone. Major side effects necessitated a change to intravenous pentamidine in 17 treated with trimethoprimsulphamethoxazole and only nine treated with trimethoprim-dapsone. Severe biochemical hepatitis occurred in six and severe neutropenia in five given trimethoprimsulphamethoxazole and in one each receiving dapsone-trimethoprim; rash and nausea and vomiting occurred with equal frequency in the two treatment groups. Asymptomatic methaemoglobinaemia occurred in most patients receiving trimethoprim-dapsone, reaching $20 \%$ in only one patient; mild hyperkalaemia (5.1-6.1 mmol/1) occurred in 16 of the patients treated with dapsone-trimethoprim.

In this study the two oral treatments appeared equally effective for the treatment of mild to moderate pneumocystis pneumonia, dapsone-trimethoprim being better tolerated. This combination is now widely used in both North America and the United Kingdom for the treatment of mild to moderate pneumocystis pneumonia.

\section{$B W 566$}

The AIDS Clinical Trials Group (ACTG) protocol 167 compared oral BW566 at a dose of $750 \mathrm{mg}$ three times daily with oral cotrimoxazole (sulphamethoxazole $1600 \mathrm{mg}$ and trimethoprim $320 \mathrm{mg}$-that is, $75 \%$ of conventionally used doses) three times daily for 21 days in 408 patients with mild to moderate pneumocystis pneumonia; 322 had cytologically confirmed disease and 86 had a clinical diagnosis (13th ACTG meeting, Washington, December 1991; unpublished data).

One hundred and sixty patients received BW566 (114 of whom had mild disease) and 162 received co-trimoxazole (115 had mild disease). Response rates were identical at $60 \%$ (96 responders to BW566 and 98 to cotrimoxazole). Toxicity occurred in 11 patients receiving BW566 and 31 receiving cotrimoxazole. Abnormalities in liver function tests occurred in $7.5 \%$ of those receiving cotrimoxazole versus $0.5 \%$ of those receiving BW566, rash in $7 \%$ versus $3 \%$, and nausea or vomiting in $6.5 \%$ versus $1 \%$. The drug fever $(5 \%)$ and leucopenia (3\%) seen with cotrimoxazole did not occur with BW566. This study showed that BW566 had a better toxicity profile than co-trimoxazole while showing equal efficacy.

\section{Other second line drugs}

Other second line drugs that have shown efficacy in the treatment of pneumocystis pneumonia, including piritrexin, trimetrexatefolinic acid, and clindamycin-primaquine, have not gained widespread use; there are few data comparing them with high dose cotrimoxazole or intravenous pentamidine.

\section{TREATMENT FOR SEVERE PNEUMONIA \\ Glucocorticoids}

Some clinicians have suggested that antipneumocystis treatment may cause an initial rapid acceleration of intrapulmonary inflammation. Further reductions in arterial oxygenation are often seen in the first three to five days of treatment, even in patients with mild disease at presentation. ${ }^{29} 30$ Possibly the death of $P$ carinii organisms exacerbates intrapulmonary inflammation. ${ }^{30}$ If this is so, beneficial effects of corticosteroids might be expected if they are begun before further lung inflammation has occurred.

Adjunctive treatment with corticosteroids for severe AIDS associated Pneumocystis carinii pneumonia was initially advocated as a means of preventing death in patients who developed respiratory failure. ${ }^{29}$ Others believed that corticosteroids were contraindicated because other life threatening 
opportunist infections would increase and Kaposi's sarcoma would spread more rapidly. In May 1990 the United States National Institutes of Health convened a consensus panel that reviewed data from five randomised trials. ${ }^{31}$ In four studies steroids were part of initial treatment and in the fifth study they were added only when treatment failed. One study was larger ${ }^{32}$ and so was given greater weight and the other studies were used to support or contrast with data from this study. The details of the studies are given in table 3.

Study 1 The Californian Collaborative Treatment Group study enrolled patients with proved $(n=220)$ or presumed $(n=31)$ pneumocystis pneumonia in an open, randomised study. Entry criteria were a hypoxaemia ratio (the ratio of arterial oxygen pressure to the fraction of inspired oxygen) of 75 or more and treatment for pneumocystis pneumonia of up to 36 hours. Prednisolone was started at $40 \mathrm{mg}$ twice daily and continued at reducing doses for 21 days. Three end points-failure of oxygenation (a hypoxaemia ratio below 75), the use of mechanical ventilation, and death-were reduced by half in those receiving corticosteroids. In patients who had the lowest levels of oxygenation overall mortality after 31 days was reduced from $43 \%$ to $19 \%$. The mode of action appeared to be prevention of further decline in oxygenation during the first three days of treatment. Adverse effects of corticosteroids included higher rates of oral candidiasis and herpes simplex infection.

Study 2 This was an open, randomised study that compared adjunctive intravenous methylprednisolone $(0.5 \mathrm{mg} / \mathrm{kg}$ four times daily for 10 days) with standard treatment alone for a first episode of pneumocystis pneumonia. Patients had an arterial oxygen pressure $\left(\mathrm{PaO}_{2}\right)$ of less than $67.5 \mathrm{~mm} \mathrm{Hg}(9.0 \mathrm{kPa})$ or a carbon dioxide pressure $\left(\mathrm{PaCO}_{2}\right)$ of less than $30 \mathrm{~mm} \mathrm{Hg}$ $(4.0 \mathrm{kPa})$ at rest and had been having antipneumocystis treatment for up to 24 hours. Fifty three patients had been studied by the time of the National Institutes of Health consensus meeting, when this study was terminated. Gastrointestinal haemorrhage and two episodes of acute psychosis occurred in the group treated with steroid. There were two deaths $(7 \%)$ in those given steroids and eight deaths $(32 \%)$ in those receiving standard treatment alone.

Study $3^{33}$ This was a randomised, double blind study which compared reducing doses of intravenous methylprednisolone (beginning with $60 \mathrm{mg}$ every six hours for eight days) with standard treatment alone. Patients were enrolled if their $\mathrm{PaO}_{2}$ was less than $51 \mathrm{~mm} \mathrm{Hg}$ $(6.8 \mathrm{kPa})$. Eleven patients were enrolled within 48 hours of starting antipneumocystis treatment, and 30 others entered after 48 hours. In the 41 patients enrolled (19 received steroids and 22 placebo) no benefit in survival after 21 and 51 days was found. There were no differences in arterial oxygen pressure or radiographic appearances between those receiving steroid and placebo. Three opportunist infections occurred in patients taking steroid.

Study $4^{34}$ This randomised, double blind, placebo controlled study enrolled 38 patients who had either an oxygen saturation of $85-90 \%$ at rest or a $5 \%$ fall in oxygen saturation on exercise. Prednisolone (60 mg daily) or placebo was given for 21 days, beginning within 48 hours of the start of antipneumocystis treatment. In $42 \%$ of patients given placebo and $6 \%$ of those given prednisolone deterioration in oxygenation reached the study end point (a

Table 3 Studies of adjunctive corticosteroid treatment in Pneumocystis carinii pneumonia

\begin{tabular}{|c|c|c|c|c|c|}
\hline Study: & $1^{31}$ & $2^{30}$ & $3^{32}$ & $4^{33}$ & $5^{34}$ \\
\hline No of patients & 251 & 53 & 41 & 38 & 23 \\
\hline Randomised & Yes & Yes & Yes & Yes & Yes \\
\hline Placebo controlled & No & No & Yes & Yes & Yes \\
\hline Oxygenation entry criteria & $\begin{array}{l}\text { Hypoxaemia } \\
\text { ratio }>75\end{array}$ & $\mathrm{PaO}_{2}<9 \mathrm{kPa}$ (air) & $\mathrm{PaO}_{2}<6.8 \mathrm{kPa}($ air $)$ & $\begin{array}{l}\mathrm{SaO}_{2} 85-90 \% \text { on air } \\
\text { or } \geqslant 5 \% \text { decrease } \\
\text { on exercise }\end{array}$ & $\begin{array}{l}\mathrm{PaO}_{2}<10 \mathrm{kPa} \text { at } \mathrm{FiO}_{2} \\
\quad=35 \%\end{array}$ \\
\hline $\begin{array}{l}\text { Maximum interval } \\
\text { between initiation of } \\
\text { antipneumocystis drug } \\
\text { and corticosteroid } \\
\text { (hours) }\end{array}$ & 36 & 24 & Unlimited & 48 & 72 \\
\hline $\begin{array}{l}\text { Corticosteroid treatment: } \\
\text { Drug (route) } \\
\text { Initial dose }\end{array}$ & $\begin{array}{l}\text { Prednisolone (oral) } \\
40 \mathrm{mg} \text { bd }\end{array}$ & $\begin{array}{l}\text { Methylprednisolone } \\
\text { (IV) } 0.5 \mathrm{mg} / \mathrm{kg} \mathrm{qds}\end{array}$ & $\begin{array}{l}\text { Methylprednisolone } \\
\text { (IV) } 60 \mathrm{mg} \text { qds }\end{array}$ & $\begin{array}{l}\text { Prednisolone (oral) } \\
60 \mathrm{mg} \text { daily }\end{array}$ & $\begin{array}{l}\text { Methylprednisolone } \\
\text { (IV) } 40 \mathrm{mg} \text { qds }\end{array}$ \\
\hline Duration (days) & 21 & 10 & 8 & 21 & $7-10$ \\
\hline $\begin{array}{l}\text { Outcome (\% given corticoste } \\
\text { Dcath } \\
\text { IPPV } \\
\text { Subsequent fall in } \\
\text { oxygenation }\end{array}$ & $\begin{array}{l}\text { oid } v \% \text { given no stero } \\
14 / 29 \\
15 / 33 \\
17 / 37\end{array}$ & $\begin{array}{l}7 / 32 \\
11 / 44 \\
\text { NA }\end{array}$ & $\begin{array}{l}31 / 37 \\
\text { NA } \\
\text { NA }\end{array}$ & $\begin{array}{l}6 / 10 \\
\text { NA } \\
\text { NA }\end{array}$ & $\begin{array}{l}25 / 82 \\
25 / 82 \\
\text { NA }\end{array}$ \\
\hline
\end{tabular}

IPPV_intermittent positive pressure ventilation; bd-twice daily; $\mathrm{PaO}_{2}$-arterial oxygen tension; qds-four times daily; $\mathrm{NA}-$ not available; SaO arterial oxygen saturation; $\mathrm{FiO}_{2}$ - fractional inspired oxygen. 
$10 \%$ decrease in oxygen saturation). Patients initially treated with adjunctive prednisolone also had longlasting improvements in exercise tolerance.

Study $5^{35}$ This randomised, double blind study compared $40 \mathrm{mg}$ of methylprednisolone every six hours with placebo for seven to 10 days in patients with severe pneumocystis pneumonia (defined by a respiratory rate of more than $30 / \mathrm{min}$, an alveolar arterial gradient of more than $30 \mathrm{~mm} \mathrm{Hg}(4.0 \mathrm{kPa})$, and $\mathrm{a} \mathrm{PaO}_{2}$ of less than $75 \mathrm{~mm} \mathrm{Hg}(10.0 \mathrm{kPa})$ with $35 \%$ oxygen but higher than $60 \mathrm{~mm} \mathrm{Hg}(8.0 \mathrm{kPa})$ with $100 \%$ oxygen). Steroids were started within 72 hours of initial antipneumocystis treatment. The study was stopped after 23 patients had been enrolled, because nine of the 12 patients taking steroid survived until hospital discharge but only two of the 11 receiving placebo did.

The conclusions of the consensus panel were that adjunctive corticosteroid treatment clearly reduced the likelihood of death, respiratory falture, or deterioration in oxygenation in patients with moderate to severe pneumocystis pneumonia. Only one study (study 3 ) did not show benefit and this differed in that it allowed late corticosteroid treatment (that is, rescue treatment) whenever respiratory failure occurred and most of the patients received corticosteroid treatment more than 72 hours after specific antipneumocystis treatment had been started. The panel suggested, firstly, that adjunctive steroids should be given to all patients who presented with $\mathrm{a}^{\mathrm{PaO}_{2}}$ of 70 $\mathrm{mm} \mathrm{Hg}(8.3 \mathrm{kPa})$ or less or an alveolar-arterial oxygen gradient of more than $35 \mathrm{~mm} \mathrm{Hg}(4 \cdot 7$ $\mathrm{kPa})$. The panel also felt that those patients with mild hypoxaemia $\left(\mathrm{PaO}_{2}\right.$ above $70 \mathrm{~mm} \mathrm{Hg}-9 \cdot 3 \mathrm{kPa}$ ) might also benefit from steroids, though it would be difficult to show this benefit as there was a good outcome in this group anyway. The panel suggested, secondly, that adjunctive glucocorticoid treatment should begin at the start of specific antipneumocystis treatment. In some patients this would be on a presumptive diagnosis of pneumocystis pneumonia and clearly there was a need to confirm the diagnosis rapidly in these circumstances. Thirdly, it was suggested that prednisolone $40 \mathrm{mg}$ twice daily should be used for the first five days, reducing to $40 \mathrm{mg}$-nce daily for the sixth to the 10th day and then $20 \mathrm{mg}$ daily for the 11 th to the 21 st days. Atternatively, intravenous methylprednisolone at $75 \%$ of the above doses was suggested. The panel emphasised that these regimens might not be better than others that had been reported.

In the United Kingdom a regimen commonly used is to give $1 \mathrm{~g}$ of methylprednisolone intravenously on three consecutive days without tapering the dose. In those responding to this regimen no rebound deterioration has been reported. ${ }^{29}$ In patients showing only a partial response further doses may be beneficial $-0.5 \mathrm{~g}$ methylprednisolone may be given for four days, with the dose tapered thereafter to $40 \mathrm{mg}$ of prednisolone by mouth and reduced to zero over 10 days.

EFLORNITHINE FOR SALVAGE TREATMENT

Thirty one patients with pneumocystis pneumonia (first episode in 27 patients and second episode in four) who had failed to respond to treatment with pentamidine, cotrimoxazole, or both were treated with eflornithine at a dose of $400 \mathrm{mg} / \mathrm{kg}$ a day intravenously in divided doses. Twenty one of the 31 patients $(68 \%)$ responded. ${ }^{36}$ Failure of response to co-trimoxazole or pentamidine was defined as three or more of the following: (1) $\mathrm{PaO}_{2}$ below $9.0 \mathrm{kPa}$ with the patient breathing air; (2) an increasing respiratory rate; (3) a deteriorating chest radiograph; (4) persistent fever after at least four days of treatment. Response to eflornithine was defined as survival to discharge with an improved chest radiograph and a normal respiratory rate and arterial blood gases during the breathing of air with no fever. Of the 31 patients receiving eflornithine, 21 survived and 10 died. Three of the survivors also received methylprednisolone, as did two of those who died. All three patients who were ventilated and received eflornithine died. Adverse reactions included bone marrow suppression in 15 patients, severe enough in five to require discontinuation of the drug. Sixteen patients had infusion phlebitis. One patient had an early relapse (within one month) despite instigation of secondary prophylaxis.

\section{CONTINUOUS POSITIVE AIRWAYS PRESSURE} VENTILATION

Continuous positive airways pressure ventilation by either nasal mask or face mask is used as a means of improving oxygenation in hypoxaemic patients with pneumocystis pneumonia. It acts, as in other conditions, by improving ventilation-perfusion relationships within the lungs, probably by holding narrow, poorly compliant airways open. ${ }^{37}$ In patients with deteriorating arterial oxygen tensions continuous positive airways pressure ventilation via face mask improves oxygenation and "buys time" whilespecificantimiebriat drugs act and also enables discussion about whether to continue treatment to be undertaken with the patient and next of kin. ${ }^{37}$

\section{Prophylaxis of Pneumocystis carinii pneumonia}

In 1989 the United States Centres for Disease Control made recommendations for the primary and secondary prophylaxis of Pneumocystis carinii pneumonia. These were that primary prophylaxis should be given to HIV positive patients with CD4 ( $\mathrm{T}$ helper lymphocyte) counts below $0.2 \times 10^{6} / 1$ or to HIV positive patients with persistent, unexplained fever or oral candidiasis irrespective of their CD4 count. ${ }^{38}$ Secondary prophylaxis should be given to all HIV positive patients after an episode of pneumocystis pneumonia. It was suggested at the time that prophylaxis should be with either oral co-trimoxazole 960 mg daily or nebulised pentamidine. The data 
were insufficient at that time to support alternative regimens such as the use of dapsone, dapsone and trimethoprim, Fansidar (sulfadoxine and pyrimethamine), or intermittent intravenous pentamidine.

The dose of pentamidine suggested was 300 $\mathrm{mg}$ of pentamidine isethionate given once a month via a Respirgard II nebuliser. The basis for this dosage came from the San Francisco Community Group prophylaxis trial. ${ }^{39}$ This trial recruited 408 patients for secondary prophylaxis. Patients were randomised to receive 30 or $150 \mathrm{mg}$ of pentamidine once a fortnight, or $300 \mathrm{mg}$ once a month. All patients received pentamidine via a Respirgard II nebuliser. Eighteen months after randomisation there had been 22 episodes of pneumocystis pneumania in the group treated with $30 \mathrm{mg}$ of pentamidine and 16 in those treated with $150 \mathrm{mg}$ fortnightly, and in those treated with $300 \mathrm{mg}$ once a month only eight patients had relapsed. The difference in relapse rate between those receiving $30 \mathrm{mg}$ fortnightly and those receiving $300 \mathrm{mg}$ monthly was significant.

At the 13th AIDS Clinical Trials Group meeting in Washington in December 1991 the results of protocol 021 were presented in advance of publication. This protocol looked at secondary prophylaxis and compared cotrimoxazole $960 \mathrm{mg}$ once a day with nebulised pentamidine $300 \mathrm{mg}$ once a month via a Respirgard II nebuliser in 310 patients, who were all receiving zidovudine. The study design was such that patients who were intolerant to either treatment were automatically switched to the alternative for ongoing prophylaxis. All patients were recruited within 10 weeks of an episode of pneumocystis pneumonia and all had received less than two weeks of alternative prophylaxis before entering the study. Some patients who had previously reacted adversely to high dose co-trimoxazole were also included. The end point of the study was time to relapse of pneumocystis pneumonia, time to development of extrapulmonary pneumocystosis (both cytologically confirmed), or survival time. Of the 310 patients recruited, 154 received co-trimoxazole and 156 received nebulised pentamidine. When the study ended there had been 50 relapses -14 in the group treated initially with co-trimoxazole and 36 in the group receiving nebulised pentamidine. Seven of the 14 patients in the co-trimoxazole arm had changed treatment because of adverse reactions to co-trimoxazole and so were taking nebulised pentamidine when they relapsed. Reanalysis of the data according to the drug that patients were taking at the time of relapse showed that seven patients were receiving cotrimoxazole and 43 were receiving nebulised pentamidine. In addition, the relapses that occurred were seen earlier in those receiving nebulised pentamidine. Mortality in the two groups was similar: 43 patients in the cotrimoxazole arm died and 47 in the nebulised pentamidine arm. Five of these deaths were due to pneumocystis pneumonia (three patients were having co-trimoxazole and two pentamidine). Change of treatment was due to haematological or dermatological toxicity. The study showed that there was no increase in zidovudine toxicity caused by simultaneous treatment with co-trimoxazole at a dose of 960 mg daily. Furthermore, patients who had had adverse reactions to high dose co-trimoxazole for treatment of pneumocystis pneumonia did not have increased side effects while taking the drug at a lower dose for prophylaxis.

Some prophylaxis against cerebral toxoplasmosis in those patients receiving cotrimoxazole was also apparent from this study. Ten patients devetoped toxplasmosis while in the study, six in the group originally treated with co-trimoxazole and four in those receiving nebulised pentamidine. At the time the toxoplasmosis developed only one patient was receiving co-trimoxazole; five other patients had changed to nebulised pentamidine because of co-trimoxazole toxicity, so that nine patients with toxoplasmosis were receiving nebulised pentamidine at the time of presentation. There was an equal incidence of bacterial infections in the two groups, but bacterial infections occurred earlier in the patients treated with nebulised pentamidine.

On the basis of this study the United States Public Health Service Task Force on AIDS recommended co-trimoxazole $960 \mathrm{mg}$ daily for first line primaryand secondary prophylaxis at the end of 1991. Monthly nebulised pentamidine was recommended as second line treatment, to be reserved for patients intolerant to the first line treatment. The task force considered that the data were insufficient to support the use of alternative regimens, though they acknowledged that drugs such as dapsone, with or without trimethoprim, were widely used for both primary and secondary prophylaxis.

Other concerns have been raised about the use of nebulised pentamidine for prophylaxis of pneumocystis pneumonia. Firstly, there are several reports of adverse reactions-occurring in health care worker, particularly in those supervising patients receiving nebulised pentamidine; these adverse reactions include circumoral paraesthesia, bronchospasm, and cough. ${ }^{40}$ In addition, a progressive decline in the transfer factor for carbon monoxide has been reported in a respiratory function technician who worked in a room adjacent to the one used for nebulising pentamidine. ${ }^{41}$ Yet serial transfer factor measurements in patients having nebulised pentamidine show no sequential decline. These problems may be reduced by ensuring that nebulisation occurs in an isolated area, preferably in a dedicated room with an extractor fan, or if putients, once instructed in the technique, are allowed to nebulise pentamidine in their own home.

In areas of high prevalence of tuberculosis there is concern that nebulisation may increase the risk of the nosocomial transmission of tuberculosis because patient during the procedure, thus generating droplet aerosol that is dispersed into the environment.

As this form of prophylaxis is not systemic and there is minimal or no systemic absorption of the drug there is a risk that it may not suppress the development of extrapulmonary 
pneumocystosis. In the largest reported series of patients with extrapulmonary pneumocystosis seven of the eight patients had received prior prophylaxis with nebulised pentamidine. ${ }^{42}$

Concerns have been expressed about the long term toxicity to the lungs of patients receiving this drug by the aerosol route. When used for nebulisation in water pentamidine is supersaturated, acidic, and hypo-osmolar. ${ }^{43}$ There are reports of the drug crystallising out within the lung, ${ }^{4}$ inducing a granulomatous résponse, ${ }^{18}$ or being associated with apical bullous change and accelerated emphysema. ${ }^{45}$

Compliance with long term treatment with nebulised pentamidine is also thought to be poor. In a study of primary and secondary prophylaxis for pneumocystis pneumonia with nebulised pentamidine at a dose of $150 \mathrm{mg}$ fortnightly compliance (defined as attendance within three days of the prescribed date for treatment) was only $23 \% .^{46}$ This study did not compare the compliance rate with that of patients receiving co-trimoxazole, dapsone, or Fansidar.

\section{EFFECTS OF NEBULISED PENTAMIDINE ON THE DIAGNOSTIC YIELD FROM BRONCHOALVEOLAR LAVAGE FLUID AND INDUCED SPUTUM}

A retrospective study of 52 patients undergoing fibreoptic bronchoscopy to diagnose pneumocystis pneumonia analysed the yield from lavage in those who had and had not received prior nebulised pentamidine prophylaxis. Twerity one patients had received prior nebulised pentamidine. ${ }^{47}$ The yield of pneumocystsis from bronchoalveolar lavage fluid was $62 \%$ in these patients and $100 \%$ in the 31 patients who had not received prior nebulised pentamidine. Transbronchial biopsy specimens were positive for $P$ carinii in 13 of 16 patients $(81 \%)$ who had received prior neburised pentamidine and in 16 of 19 patients $(84 \%)$ who had not. Five clumps of $P$ carinii per slide were seen on average for those who had received prior nebulised pentamidine and 20 for those with no prior prophylaxis with pentamidine. ${ }^{47}$

This study also compared the radiographic appearances in those patients who had received prior nebulised pentamidine and in those who had not. Radiographic changes were "typical" in 28 patients ( $90 \%$ ) who had not received prior pentamidine but in only $11(52 \%)$ who had received pentamidine. Two patients $(7 \%)$ with no prior prophylaxis and eight patients $(38 \%)$ who had received pentamidine had predominantly upper lobe infiltrates. In addition, cystic changes were seen in five patients receiving prior prophylaxis and in only one patient with no prior prophylaxis; two patients who presented with pneumothorax had received pentamidine. The authors concluded that nebulised pentamidine prophylaxis reduced the diagnostic yield from bronchoalveolar lavage and increased the frequency of atypical radiographic appearances.

A retrospective analysis was carried out on the results of 348 induced sputum procedures performed during the initial investigations for possible pneumocystis pneumonia in a mixed population of HIV positive adults and children. Twenty nine patients were excluded as they were having prophylaxis with oral or intravenous regimens. Of the remaining 319 patients, 126 were receiving prophylaxis with nebulised pentamidine prophylaxis at the time of the sputum induction and 193 patients were receiving no prophylaxis at the time of the procedure. ${ }^{48}$ Seventy two of the 319 episodes were ultimately found to be due to pneumocystis pneumonia, on the basis of sputum induction in 54, bronchoalveolar lavage in 16, percutaneous lung biopsy in one, and necropsy in one. Of these 72 episodes, 44 occurred in patients receiving no prophylaxis and 28 in patients receiving prior prophylaxis with nebulised pentamidine. These two groups were similar in age, duration of symptoms, and arterial-alveolar oxygen gradient at the time of sputum induction. The mean $\mathrm{CD} 4$ counts were significantly lower $\left(0.2 \times 10^{6} / 1\right)$ in those who had received prior nebulised pentamidine than in those with no prior prophylaxis $\left(0.68 \times 10^{6} / 1\right){ }^{48}$

Five patients receiving no prophylaxis failed to produce a sample of sputum. Thirty six of the remaining 39 patients $(92 \%)$ produced a sample positive for $P$ carinii, compared with only 18 of 28 patients $(64 \%)$ who had received prior nebulised pentamidine. In those patients who had received no prior prophylaxis chest radiographs were normal or typical in $65 \%$; showed upper lobe predominance of infiltrate in $14 \%$; and showed other appearances, including focal (but not upper lobe) changes or cystic or cavitary abnormalities, in $2 \%$. In those who had received prior nebulised pentamidine radiographs were normal or typical of pneumocystis pneumonia in $41 \%$ and showed upper lobe predominance of infiltrates in $37 \%$ and focal or cystic-cavitary changes in $22 \%$. The conclusions of this study were that there was a significant reduction in the yield from induced sputum for the diagnosis of pneumocystis pneumonia in patients who had received prior pentamidine and in this group a larger proportion of patients had upper lobe predominance of infiltrates on the chest radiograph. ${ }^{48}$

\section{Conclusions}

The techniques of molecular biology have already begun to change much of our understanding of the basic biology and life cycle of $P$ carinii. Application of the technique of DNA amplification to specimens of bronchoalveolar lavage fluid and induced sputum have been shown to give a significantly better yield from these specimens for the diagnosis of pneumocystis infection than conventional silver staining. Possibly in the future even less "invasive" samples, such as saliva, will be used to diagnose pneumocystis pneumonia.

Patients with mild to moderate pneumonia may be given oral treatment. Dapsonetrimethoprim appears to be as effective as oral co-trimoxazole and better tolerated by patients. The new agent BW566 also appears promising, with efficacy similar to that of cotrimoxazole and with a better toxicity profile. 
Glucocorticoid treatment is now well established for patients with severe pneumocystis pneumonia and should be offered to all patients with suspected or proved pneumocystis pneumonia who have an arterial oxygen tension of $8.0 \mathrm{kPa}$ or less in addition to parenteral cotrimoxazole or pentamidine. Primary prophylaxis for pneumocystis infection should be offered to HIV positive patients with $\mathrm{CD} 4$ counts below $0.2 \times 10^{6} / 1$ and to those with unexplained persistent fever or oral candidiasis regardless of their CD4 count; and secondary prophylaxis should be offered to all patients after an episode of pneumocystis pneumonia. The prophylactic agent of choice is daily oral co-trimoxazole.

1 Peglow SL, Smulian AG, Linke MJ, Pogue CL, Nurre S, Crisler J, et al. Serologic responses to Pneumocystis carinii antigens in health and disease. $J$ Infect Dis 1990;161: 296-306.

2 Wakefield AE, Steward TJ, Moxon ER, Marsh K, Hopkin JM. Infection with Pneumocystis carinii is prevalent in healthy Gambian children. Trans $R$ Soc Trop Med 1990; 84:800-2.

3 Wakefield AE, Hopkin JM, Burns J, Hipkiss JB, Stewart TJ, Moxon ER. Cloning of DNA from Pneumocystis carinii. J Infect Dis 1988;158:859-62.

4 Wakefield AE, Pixley FJ, Banerii S, Sinclair K, Miller RF, Moxon ER, et al. Amplification of mitochondrial ribosomal RNA sequences from Pneumocystis carinii DNA of rat and human origin. Molec Biochem Parasitol 1990;43:69-76.

5 Sinclair K, Wakefield AE, Banerji S, Hopkin JM Pneumocystis carinii organisms derived from rat and human hosts are genetically distinct. Molec Biochem Parasitol 1991;45:183-4.

6 Peters SE, Wakefield AE, Banerji S, Hopkin JM. Quantification of the detection of Pneumocystis carinii by DNA amplification. Molecular and Cellular Probes (in press).

7 Millard PR, Heryet AR. Observations favouring Pneumocystis carinii pneumonia as a primary infection: a monoclonal antibody study on paraffin sections. $J$ Pathol 1988; 154:365-70.

8 Peters SE, Wakefield AE, Sinclair K, Millard PR, Hopkin JM. A search for Pneumocystis carinii in post mortem lung by DNA amplification. $J$ Pathol 1992;166:195-8.

9 Wakefield AE, Pixley FJ, Banerji S, Sinclair K, Miller RF, Moxon ER, et al. Detection of Pneumocystis carinii with DNA amplification. Lancet 1990;336:451-3.

10 Wakefield AE, Guiver L, Miller RF, Hopkin JM. DNA amplification on induced sputum samples for diagnosis of Pneumocystis carinii pneumonia. Lancet 1991;337:1378-9.

11 Jacobs JL, Libby DM, Winters RA, Gelmont DM, Fried ED, Hartman BJ. A cluster of Pneumocystis carini pneumonia in adults without predisposing illnesses. $N$ Engl J Med 1991;324:246-9.

12 Rucbush TK, Weinstein RA, Bachner RL. An outbreak of pneumocystis pneumonia in children with acute lymphocytic leukaemia. Am J Dis Child 1978;132:143-48.

13 Edman JC, Kovacs JA, Masur H, Santi D, Elwood H, Sogin M. Ribosomal RNA sequences show Pneumocystis carini to be a member of the fungi. Nature 1988;334:519-22.

14 Watanabe JI, Hori H, Tanabe K, Nakamura Y. $5 S$ ribosomal RNA sequence of Pneumocystis carinii and its phylogenetic association with Rhizopoda/Myxomycota/Zygomycota groups. J Protozool 1989;36:17-9S

15 Pixley FJ, Wakefield AE, Banerji S, Hopkin JM. Mitochondrial gene sequences show fungal homology for Pneumocystis carinii. Molec Microbiol 1991;5:1347-51.

16 Miller RF, Miller AB, Weller IVD, Semple SJG. Empirical treatment without bronchoscopy for Pneumocystis carini pneumonia in the acquired immunodeficiency syndrome. Thorax 1989;44:559-64.

17 Robinson DS, Cunningham DA, Dave S, Fleming J Mitchell DM. Diagnostic value of lung clearance of ${ }^{99 \mathrm{~m}} \mathrm{Tc}$ DTPA compared with other non-invasive investigations in Pneumocystis carinii pneumonia in AIDS. Thorax 1991;46:722-6.

18 Birley HDL, Buscombe JR, Griffiths MH, Semple SJG, Miller RF. Granulomatous Pneumocystis carini pneumonia in a patient with the acquired immunodeficiency syndrome. Thorax 1990;45:769-71.

19 Miller RF. Nuclear Medicine and AIDS. Eur J Nucl Med 1990;16:103-18.

20 Fishman JA, Strauss HW, Fischman AJ, Nedelman M, Callahan R, Khaw B-A, et al. Imaging of Pneumocystis clonal IgG: an experimental study in rats. $\mathrm{Nucl} \mathrm{Med}$ Commun 1991;12:175-87.

21 Miller RF, Buscombe J, Grant A, Oyen W, Lui D, Claessens $R$, et al. Investigation of acute respiratory illness in HIV positive patients using indium labelled polyclonal immunoglobulin scans. Thorax (in press)

22 Leigh TR, Parsons P, Hume C, Husain OAN, Gazzard B,
Collins JV. Sputum induction for diagnosis of Pneumocystis carinii pneumonia. Lancet 1990;ii:205-6.

23 Miller RF, Kocjan G, Buckland J, Holton J, Malin A, Semple SJG. Sputum induction for the diagnosis of pulmonary disease in HIV positive patients. $J$ Infect 1991; 23:5-15.

24 Miller RF, Buckland J, Semple SJG. Arterial desaturation in HIV positive patients undergoing sputum induction. Thorax 1991;46:449-51.

$25 \mathrm{Ng}$ VL, Yajko DM, McPhaul LW. Evaluation of an indirect fluorescent antibody stain for detection of Pneumocystis carinii in respiratory specimens. J Clin Microbiol 1990; 28:975-9.

26 Cregan P, Yamamoto A, Lum A, Van der Heide T, MacDonald M, Pulliam L. Comparison of four methods for rapid detection of Pneumocystis carinii in respiratory specimens. J Clin Microbiol 1990;28:2432-6.

27 Sattler F, Cowan R, Neilsen DM, Ruskin J. Triethoprimsulfamethoxazole compared with pentamidine for treatment of Pneumocystis carinii pneumonia in the acquired immunodeficiency syndrome: a prospective non-crossover study. Ann Intern Med 1988;109:280-7.

28 Medina I, Mills J, Leoung G, Hopewell PC, Lee B, Modin G, et al. Oral therapy for Pneumocystis carinii pneumonia in the acquired immunodeficiency syndrome. $N$ Engl $J$ Med 1990;323:776-82.

29 Miller RF, Mitchell DM. Management of respiratory failure in patients with the acquired immunodeficiency syndrome and Pneumocystis carinii pneumonia. Thorax 1990;45: $140-6$.

30 Miller RF, Roberts CM. Intensive care management of HIV positive patients and patients with AIDS. Clin Intens Care 1991;2:17-25.

31 Consensus statement on the use of corticosteroids as adjunctive therapy for pneumocystis pneumonia in the acquired immunodeficiency syndrome. $N$ Engl J Med 1990;323: $1500-4$.

32 Bozzette SA, Sattler FR, Chiu J, Wu AW, Gluckstein D, Kemper C, et al. A controlled trial of early adjunctive treatment with corticosteroids for Pneumocystis carinii pneumonia in the acquired immunodeficiency syndrome. N Engl J Med 1990;323:1451-7.

33 Clement M, Edison R, Turner J, Montgomery B, Luce J, Feigal D, et al. Corticosteroids as adjuvant therapy in severe Pneumocystis carinii pneumonia [abstract]. Am Rev Respir Dis 1989;139:A250.

34 Montaner JSG, Lawson LM, Levitt N, Belzberg A, Schechter MT, Ruedy J. Corticosteroids prevent early deterioration ' in patients with moderately severe Pneumocystis carinii pneumonia and the acquired Pneumocystis carinii pneumonia and the acquired
immunodeficiency syndrome (AIDS). Ann Intern Med 1990;113:14-20.

35 Gagnon S, Boota AM, Fischl MA, Baier H, Kirksey DW, LaVoie L. Corticosteroids as adjunctive therapy for severe Pneumocystis carinii pneumonia in the acquired immunodeficiency syndrome. N Engl J Med 1990;323:1444-50.

36 Smith D, Davis S, Nelson M, Youle M, Gleeson J, Gazzard B. Pneumocystis carinii pneumonia treated with eflornithine in AIDS patients resistant to conventional therapy. AIDS 1990;4:1019-21.

37 Miller RF, Semple SJG. Continuous positive airway pressure ventilation for respiratory failure associated with Pneumocystis carinii pneumonia. Respir Med 1991;85: 133-8.

38 Girard PM, Pocidalo JJ, Murray JF. Primary prophylaxis against common infectious diseases in person with human immunodeficiency virus infection. Am Rev Respir Dis 1991;143:447-50.

39 Leoung GS, Feigal DW, Montgomery AB, Corkery K, Wardlaw $\mathrm{P}$, Adams $\mathrm{M}$, et al. Aerosolized pentamidine for prophylaxis against Pneumocystis carinii pneumonia. N Engl J Med 1990;323:769-75.

40 Green ST, Nathwani D, Christie PR, Kennedy DH. Aerosolized pentamidine. Lancet 1989;ii: 1284

41 Gude JK. Selective delivery of pentamidine to the lung by aerosol. Am Rev Dis 1989;139:1060.

42 Coker RJ, Clark D, Clayton EL, Ainsworth JG, Lucas SB, Miller R, et al. Disseminated Pneumocystis carinii infection in AIDS. J Clin Pathol 1991;44:820-3.

43 Miller RF, Steel SJ. Nebulised pentamidine as prophylaxis for Pneumocystis carinii pneumonia. J Antimicrob Chemother 1991;27:153-60.

44 McGowan I, Potter M, George RJD, Michaels L, Scaravilli F, Miller RF. HIV encephalopathy presenting as hypomania: clinico-pathological conference. Genitourinary Med 1991;67:420-4.

45 Miller RF, Semple SJG, Lucas SB. Premature bullous pulmonary damage in AIDS. Genitourinary Med 1991; 67:4-9.

46 West D, Steel S, Miller R. Audit of Pneumocystis carinii prophylaxis in Bloomsbury Health Authority. Int $J$ Pharmac Pract 1991;1:23-6.

47 Jules-Elysee KM, Stover DE, Saman MB, Bernard EM, White DA. Aerosolized pentamidine: effect on diagnosis and presentation of Pneumocystis carinii pncumonia. Ann Intern Med 1990;112:750-7.

48 Levine SJ, Masur H, Gill VJ, Fuerstein I, Suffredini AF, Brown D, et al. Effect of aerosolized pentamidine prophylaxis on the diagnosis of Pneumocystis carinii pneumonia by induced sputum examination in patients infected with the human immunodeficiency virus. Am Rev Respir Dis $1991 ; 144: 760-4$. 